FITRAH Jurnal Kajian Ilmu-ilmu Keislaman

Vol. 05 No. 1 Juni 2019

e-ISSN : 2460-2345, p-ISSN: 2442-6997

Web: jurnal.iain-padangsidimpuan.ac.id/index.php/F

\title{
ANALIS SARANA DAN PRASARANA PENDIDIKAN DI LINGKUNGAN SDN 262 PANYILEUKAN KOTA BANDUNG
}

\author{
RUSLANDI, DAN CHAERUL ROCHMAN \\ Universitas Islam Negeri Sunan Gunung Djati Bandung \\ e-mail: ruslandi731@gmail.com, dan chaerulrochman@uinsgd.ac.id
}

\begin{abstract}
In the management of the school, the Headmaster must have responsible to take care of all the facilities and infrastructure. The headmaster and all of the members of the school must be able to maintain and pay attention to the facilities and infrastructure already there is. With the availability of facilities and infrastructure in schools, the students can learn maximally. The management of the schools must emphasize more attention to the facilities and infrastructure. Every people must be responsible manage and take care of these facilities and infrastructure. The head of the schools must have plans, notes, and record to any facilities and infrastructure used in the school. If all management steps have been carried out with good as expected it will have a positive impact towards students in the teaching and learning process, then the achievement of educational goals reach effectively and efficiently.
\end{abstract}

Keywoards: Facilities and Infrastructure, Education

\begin{abstract}
Abstrak
Salah satu tanggungjawab Kepala Sekolah sebagai seorang yang diberi amanah untuk menanggungjawabi sekolah yang dipimpinnya adalah mengelola sarana dan prasarana. Bahkan sekolah harus mampu menjaga dan memperhatikan fasilitas dan infrastruktur sekolah yang sudah ada. Sehingga dengan ketersediaan fasilitas dan infrastruktur di sekolah siswa dapat belajar secara maksimal dan seefisien mungkin. Jadi pengelolaan sarana dan prasarana harus lebih ditekankan di lembaga pendidikan seperti sekolah. Dan seseorang harus bertanggung jawab untuk itu manajemen fasilitas dan infrastruktur ini manajemen fasilitas dan infrastruktur di sekolah. Kepala sekolah dapat merencanakan dan mencatat segala fasilitas dan infrastruktur yang harus digunakan di sekolah. Jika semua langkah manajemen telah dilakukan dengan baik seperti yang diharapkan itu akan memiliki dampak positif terhadap siswa dalam proses belajar mengajar dan pencapaian tujuan pendidikan secara efektif dan efisien.
\end{abstract}

Kata Kunci: Sarana dan Prasarana, Pendidikan 
FITRAH Jurnal Kajian Ilmu-ilmu Keislaman

Vol. 05 No. 1 Juni 2019

\section{PENDAHULUAN}

Pengelolaan sarana dan prasarana sangat penting dalam lembaga pendidikan, karena dengan sarana dan prasaran yang baik dan terjaga menentukan kualitas dari lembaga tersebut, sehingga kegiatan belajar mengajar menjadi lebih mudah dan efisien.

Dalam UU no. 20 Tahun 2003 tentang SISDIKNAS dibahas betapa pentingnya sarana dan prasarana di sebuah lembaga pendidikan:

"Setiap satuan pendidikan formal dan non formal menyediakan sarana dan prasarana yang memenuhi yang memenuhi keperluan pendidikan sesuai dengan pertumbuhan dan perkembangan potensi fisik, kecerdasan intelektual, sosial, emosional, dan kewajiban peserta didik" (Undang-Undang RI Tahun 2003). Juga Peraturan Pemerintah RI No 19 tahun 2005 tentang Standar Nasional Pendidikan Bab VII pasal 42 ayat 1 dan 2:

- Setiap satuan pendidikan wajib memiliki sarana yang meliputi : perabot, peralatan pendidikan, buku dan sumber belajar lainnya, bahan habis pakai serta perlengkapan yang diperlukan untuk menunjang proses pembelajaran yang teratur dan berkelanjutan.

- Dari setiap satuan pendidikan meliputi : lahan, ruang kelas, ruang pimpinan, ruang guru, ruang perpustakaan, ruang laboratorium, kantin, tempat berolah raga dan tempat beribadah, tempat bermain, tempat berekreasi, dan ruang tempat lain yang diperlukan untuk menunjang proses pemmbelajaran yang teratur dan berkelanjutan.(PP RI Tahun 2005)

\section{METODE PENELIAN}

Penelitian ini menggunakan metode penelitian Deskriptif Kualitatif yang berarti mendeskripsikan data disertai gambaran maupun penafsiran serta menganalisis Standar Sarana dan Prasarana di sekolah.

Selain itu, penelitian ini menggunakan teknik pegumpulan data dengan cara:

1) Observasi, melakukan penelitian di lapangan

2) Wawancara, melakukan penelitian dengan mengumpulkan jawaban dari pertanyaan langsung kepada responden yang berkaitan khusus dengan 21 indikator sarana dan prasarana kepada pendidik dan tenaga kependidikan. 
3) Dokumentasi, melakukan penelitian dengan mengumpulkan data melalui beberapa arsip, majalah, jurnal, buku, dsb. Yang dianggap relevan dengan penelitian.

Adapun sumber data dalam penelitian ini yakni data primer dan data sekunder. Data primer merupakan sumber data yang diperoleh langsung, yakni data sarana dan prasarana dengan menggunakan lembar pengamatan. Adapiun sumber data sekunder yakni data yang diperoleh dari hasil dokumentasi sekolah serta wawancara dengan pihak sekolah yang bersangkutan.

Data mengenai sarana dan prasarana pendidikan tersebut selanjutnya dibandingkan dengan standar minimum sarana dan prasarana dalam Permen No. 2 Tahun 2007 tentang sarana dan parasarana untuk dianalisis kelayakannya.

\section{HASIL PENELITIAN DAN PEMBAHASAN}

Berdasarkan hasil pengambilan dan analisis data tentang ketercapaian indikator Standar Sarana dan Prasarana di SDN 262 Panyileukan Kota Bandung, maka dapat dijelaskan dengan profil ketercapaian indikator Sarana dan Prasarana, komposisi Standar Sarana dan Prasarana dan alternatif pemecahan masalah sebagai berikut:

1) Profil Ketercapaian Indikator Standar Sarana dan Prasarana

Profil ketercapaian 21 Indikator Standar Sarana dan Prasarana dapat ditunjukkan melalui data sebagai berikut:



Gambar 1. Profil Ketercapaian Indikator Sarana dan Prasarana 
FITRAH Jurnal Kajian Ilmu-ilmu Keislaman

Vol. 05 No. 1 Juni 2019

Gambar diatas menunjukkan tingkat ketercapaian setiap indikator dari Sarana dan Prasarana di SDN 262 Panyileukan Kota Bandung. Pelaksanaan atau ketercapaian Standar Sarana di sekolah ini tampak sudah baik, hal ini dapat kita lihat dari banyaknya indikator yang memperoleh skor 5 (dalam artian sudah memenuhi syarat). Namun terdapat beberapa indikator yang tidak memenuhi skor maksismum yakni 7 indikator dari 21 indikator (Keseluruhan). Berdasarkan analisis hasil penelitian yang telah dilakukan di SDN 262 Panyileukan Kota Bandung, maka diperoleh informasi tentang kelemahan yang dialami untuk membantu ketercapaian Standar Sarana dan Prasarana. Hal ini dapat kita lihat dari gambar 1, yakni dari 21 Indikator ada 7 indikator yang perolehan skornya kurang dari skor maksimal. Adapun 7 indikator yang tidak mencapai skor maksimal terdiri dari 6 indikator dengan perolehan skor 1 dan 1 indikator dengan perolehan skor 3 .

Berdasarkan analisis data, dapat dinyatakan jumlah skor yang diperoleh secara keseluruhan ialah 79 dari skor maksimum 105. Sehingga dapat dinyatakan bahwa ketercapaian Standar Sarana dan Prasarana di SDN Panyileukan Kota Bandung belum sempurna atau dengan kata lain secara keseluruhan capaian Standar Sarana dan Prasarana adalah 75,2 \% (Baik).

Ketersedian dan Pemeliharaan sarana dan prasarana sangatlah penting, Hamalik (1986) pemakaian sarana atau materi pengajaran dapat meningkatkan minat dan motivasi serta rangsangan kegiatan belajar mengajar siswa yang berpengaruh secara psikologis terhadap siswa.

2) Komposisi Kualifikasi Standar Sarana dan Prasarana

Komposisi kualifikasi Standar Srana dan Prasarana dapat ditunjukkan dalam diagram sebagai berikut:

\section{Komposisi Kualifikasi Standar Sarana dan Prasarana}

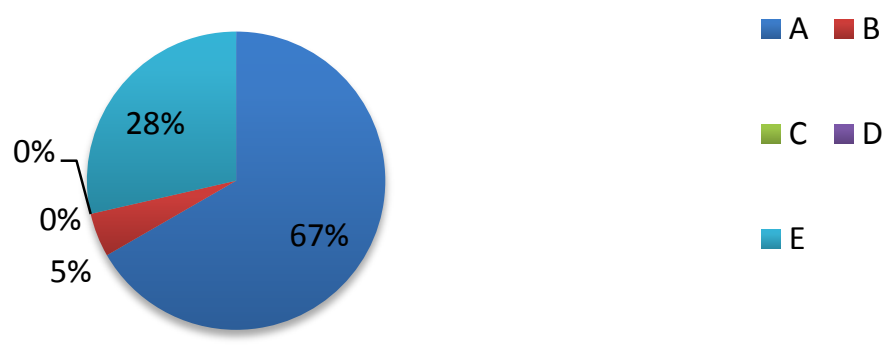

Gambar 2. Komposisi Kualifikasi Standar Srana dan Prasarana 
Gambar 2. Menunjukkan komposisi kualifikasi pemecahan masalah kesulitan dalam mencapai standar sarana dan prasarana. Sebagaimana telah dijelaskan diatas terdapat perbandingan yang signifikan. Dimana tingkat ketercapaian Standar Sarana dan Prasarana dengan skor maksimal dilambangkan dengan A yakni mendapat persentase sbanyak $67 \%$, sedangkan skor dengan nilai B, C, D mendapat persentase sebanyak 0\%, sedangkan Skor dengan nilai $\mathrm{E}$ mendapat persentase sebanyak $28 \%$.

Adapun indikator yang tergolong D dengan Indikator 1, Indikator 3, Indikator 9, Indikator 14, Indikator 20, dan indikator 21. Indikator 1 membahas tentang luas lahan dengan ketentuan luas minimum, dimana luas lahan sekolah ini dirasa tidak memenuhi ketentuan luas lahan minimum. Indikator 3 membahas tentang luas lantai dengan ketentuan luas lantai minimum, dimana luas lantai sekolah ini tidak memenuhi luas lantai minimum. Indikator 9 membahas tentang ruang kelas dengan jumlah, ukuran, dan sarana sesuai dengan ketentuan, sekolah ini tidak memenuhi ketentuan ruang kelas denganjumlah, ukuran, dan sarana sesuai dengan ketentuan. Indikator 14 membahas tentang tempat beribadah bagi warga sekolah, sekolah ini menggunakan tempat ibadah diluar sekolah. Indikator 20 membahas tetang kantin sekolah, adapun sekolah ini tidak menggunakan kantin sekolah melainkan kantin di luar sekolah (Jajanan Luar). Sedangkan indikator 21 membahas tentang lahan parkir yang sesuai ketentuan, sekolah ini tidak memiliki lahan parkir yang memadai bagi warga sekolah.

Indikator yang belum Optimal dicapai dalam penelitian ini yakni indkator 9 yaitu menyangkut ketersediaan ruang kelas yang sesuai dengan jumlah, ukuran dan sarana minimum.

Tata Ruang kelas bertujuan menciptakan proses belajar dan mengajar berjalan efektif dan efisien, sehingga dalam pelaksanaannya tujuan pembelajaran dapat tercapai secara optimal. Hal ini menunjukkan bahwa betapa pentingnya ruang kelas dikelola dengan baik dan benar.

\section{KESIMPULAN}

Berdasarkan hasil pengambilan dan analisis data tentang ketercapaian indikator Standar Sarana dan Prasarana di SDN 262 Panyileukan Kota Bandung, maka dapat dijelaskan dengan profil ketercapaian indikator Sarana dan Prasarana, komposisi Standar Sarana dan Prasarana. Tata Ruang kelas bertujuan 
FITRAH Jurnal Kajian Ilmu-ilmu Keislaman

Vol. 05 No. 1 Juni 2019

menciptakan proses belajar dan mengajar berjalan efektif dan efisien, sehingga dalam pelaksanaannya tujuan pembelajaran dapat tercapai secara optimal. Hal ini menunjukkan bahwa betapa pentingnya ruang kelas dikelola dengan baik dan benar. Pengelolaan sarana dan prasarana yang baik akan menciptkaan lingkungan belajar yang lebih baik dan akan berdampak posittif pada hasil pembelajaran yang akan dicapai oleh siswa. 


\section{DAFTAR PUSTAKA}

Awaluddin, \& Saputra, E. 2016. Sistem Informasi Manajemen Sarana Prasarana Sekolah. Jurnal Rekayasa dan Manajemen Sistem Informasi

Bafadal I. 2008. Manajemen Peningkatan Mutu Sekolah Dasar dari Sentralisasi Menuju Desentralisasi. Jakarta: Bumi Aksara.

Darmawan B. 2014. Manajemen Sarana dan Prasarana dalam Meningkatkan Pendidikan. Jurnal Pelopor Pendidikan,Vol. 6, No. (2): 95-102.

Gaspersz, V. 2005. Total Quality Management. Jakarta: Gramei Pustaka Utama.

Ismaya, B.2015. Pengelolaan Pendidikan . Bandung: Refika Aditama.

Junaidi.2010. Indikator Sarana Prasarana Pendidikan. Fakultas Ekonomi Universitas Jambi.

Oemar H. 1986. Media Pendidikan. Bandung: Alumni.

Syaiful Bahri D. 2006. Strategi Belajar Mengajar. Jakarta: PT. Rineka Cipta

Wijaya, D.2008. Implementasi Manajemen Mutu Terpadu dalam Penyelenggaraan Pendidikan di Sekolah. Jurnal Pendidikan Penabu.

Wiyono, B. 2007. Metodologi Penelitian. Malang: Rasindo Malang. 
FITRAH Jurnal Kajian Ilmu-ilmu Keislaman

Vol. 05 No. 1 Juni 2019

\section{Fundraising Bagi Pemberdayaan Pendidikan pada}

\section{Panti Asuhan Hafizhil Yatamu Kota Padangsidimpuan}

\section{Darliana Sormin dan Samsidar}

Universitas Muhammadiyah Tapanuli Selatan

Email: darliana.sormin@um-tapsel.ac.id 